\title{
A CONSTITUIÇÃO \\ DO ETHOS \\ DISCURSIVO EM \\ LETRA DE \\ MODA DE VIOLA
}

\section{LA CONSTITUCIÓN DEL ETHOS DISCURSIVO EN LA LETRA DE MODA DE VIOLA}

\author{
THE CONSTITUTION OF THE DISCURSIVE ETHOS IN COUNTRY MUSIC LYRICS
}

\section{Cristiane da Silva Ferreira*}

Pontifícia Universidade Católica de São Paulo

\begin{abstract}
RESUMO: O objetivo deste artigo é investigar a constituição do ethos discursivo na letra de moda de viola Ferreirinha, produzida por Adauto Ezequiel, conhecido como Carreirinho, em 1950. Fundamentados pelo aporte teórico-metodológico da Análise do Discurso, mais especificamente o pressuposto de Maingueneau, concebemos o ethos discursivo como uma categoria de análise eficaz e interativa, uma vez que está associada ao processo de adesão dos sujeitos a um certo posicionamento. Os resultados da análise apontam que o discurso da letra de moda de viola selecionada desvela um ethos discursivo baseado em valores e estereótipos validados socialmente, principalmente, pelos migrantes rurais instalados na capital paulista.
\end{abstract}

PALAVRAS-CHAVE: ethos discursivo; moda de viola; Análise do Discurso.

RESUMEN: El objetivo de este artículo es investigar la constitución del ethos discursivo en la letra de moda de viola llamada Ferreirinha, producida por Adauto Ezequiel, conocido como Carreirinho, en 1950. Fundamentados por el aporto teóricometodológico del Análisis del Discurso, específicamente el presupuesto del Maingueneau, concebimos el ethos discursivo como una categoría de análisis eficaz y/e interactiva, una vez que es asociada al proceso de adhesión de los sujetos a un cierto posicionamiento. Los resultados de los análisis indican que el discurso en la letra de moda de viola seleccionada muestra un ethos discursivo basado en valores y estereotipos validados socialmente, principalmente por emigrantes rurales que viven en la capital de São Paulo.

PALABRAS CLAVE: ethos discursivo; moda de viola; Análisis del Discurso.

* Doutoranda no Programa de Pós-Graduação em Língua Portuguesa da Pontifícia Universidade Católica de São Paulo (PUC-SP). E-mail: crisife@bol.com.br 
ABSTRACT: The purpose of this article is to investigate the constitution of the discursive ethos in the country music lyrics of Ferreirinha, written in 1950 by Adauto Ezequiel, also known as Carreirinho. Based on the theoretical and methodological support of the analysis of speech, more specifically Maingueneau's assumption, we have conceived the discursive ethos as an effective and interactive category of analysis, since it is associated to the subjects' accession process to a given opinion. The results reveal that the speech of the analyzed country music lyrics unveils a discursive ethos based in socially validated values and stereotypes, especially by rural migrants living in the city of Sao Paulo, Brazil.

KEYWORDS: discursive ethos; country music; analysis of speech.

\section{INTRODUÇÃO}

Este artigo tem como propósito estudar a constituição do ethos discursivo na letra de moda de viola, pois essa é uma categoria que revela a imagem e a identidade do enunciador, por meio dos recursos linguísticos e discursivos. Selecionamos como objeto de análise o discurso da letra de moda de viola Ferreirinha, produzido na década de 1950, por Adauto Ezequiel, mais conhecido como Carreirinho. A canção trata de um discurso bastante difundido e conhecido nas regiões Sudeste e Centro-Oeste, consideradas o berço da cultura do homem caipira, por compor a memória discursiva destes sujeitos.

A moda de viola é um estilo musical oriundo do cancioneiro caipira, que se propagou pela capital paulista a partir da década de 1929, ano que marca sua inserção na indústria fonográfica. O responsável por essa façanha, segundo Nepomuceno (1999), foi Cornélio Pires, que levou legítimos violeiros caipiras para tocar nas rádios em São Paulo. A partir de então, a moda de viola conquistou êxito à medida que seu público, composto por migrantes rurais, ia aumentando na capital.

Ao concebermos esse discurso como prática social, entendemos que ele propala a imagem de um corpo investido de valores reconhecidos em sua formação discursiva, para ser aceito em um novo contexto. Pelas condições de produção do discurso selecionado, consideramos que o novo contexto compreende a capital paulista, impulsionada pelo espírito de modernidade e progresso.

Para embasar a análise que empreendemos, fundamentamo-nos nos pressupostos teórico-metodológicos da Análise do Discurso, doravante AD, mais especificamente no postulado enunciativo-discursivo de Maingueneau (2001), responsável por reformular, na atualidade, o conceito de ethos, advindo da retórica antiga. Ao lado dessa categoria, devemos considerar o interdiscurso e a cenografia; antes, porém, vamos apresentar as condições sócio-históricas de produção do discurso de letra selecionada para análise.

\section{CONDIÇÕES SÓCIO-HISTÓRICAS DE PRODUÇÃO DO DISCURSO DE LETRA DE MODA DE VIOLA}

O discurso de letra de moda de viola, cuja produção intensa ocorreu na década de 50, despontou em uma São Paulo que se consolidava no cenário econômico, impulsionada pela forte industrialização. Esse processo e a atração que os grandes centros urbanos exerciam sobre a população atraíram uma quantidade exponencial de migrantes rurais para a capital paulista. Dentre esses migrantes, encontravam-se, inclusive, os da classe média interiorana, cujo propósito era arriscar novos investimentos na capital.

Os migrantes provenientes das áreas rurais do Centro-Oeste, Sudeste e Nordeste do país somaram-se aos descendentes de escravos, ex-escravos e imigrantes europeus que, desde o fim do século XIX, já estavam instalados nas capitais brasileiras. Esse conjunto heterogêneo da população compôs o cenário cultural da cidade de São Paulo, em especial, promovendo o surgimento de variados movimentos estético-musicais, como a moda de viola.

O sucesso da moda de viola na capital, sobretudo, e no interior de São Paulo, e a migração rural-urbana, são dois fenômenos correlatos. A migração, embora compreenda “[...] um deslocamento geográfico, não implica num abandono das relações primárias que constituem o universo de origem, mas um rearranjo dessas relações", segundo Durhan (1973, p.138). Nesse sentido, concordamos com a autora quando afirma que a migração rural-urbana é também um fenômeno de mudança sociocultural, que 
transforma os padrões de comportamento vigentes, até então, nas comunidades rurais, para que o migrante se ajuste e se adapte às novas condições da vida urbana.

Além disso, conforme Martins (1975), o migrante era cônscio desses ajustes, para que pudesse se ressocializar em seu novo ambiente, e de quais traços culturais podia preservar sem danos para o seu processo de adaptação. Como a migração era um processo familial, segundo apurou Durhan (1973), em que os integrantes vão levando os demais membros da família, aos poucos, para a cidade, num espaço de tempo considerável, eles mesmos informavam uns aos outros sobre quais desses ajustes eram necessários. Muitos desses traços culturais, como a religiosidade, que serão apontados na análise do corpus selecionado, estavam impregnados no discurso de letras de moda de viola, com o qual o migrante se identificava. Vejamos o que diz Martins (1975, p.115) a esse respeito:

O migrante rural, marginalizado na cidade, precisava ser atendido por mensagens especiais que reorientassem seu estoque simbólico, tomando de novo o contexto rústico de origem como quadro de referência positiva, invertendo assim a posição da matriz de significações em que fora socializado por antecipação.

Martins (1975) traduz a importância da música sertaneja de raiz para esse público específico, pois o discurso das letras evoca práticas discursivas que estão impregnadas na memória discursiva destes sujeitos.

Nessa mesma direção, Tinhorão (2013) constata que o surgimento de duplas caipiras no rádio e nos discos anunciava, na realidade, a existência de um público que, dadas as suas raízes rurais, necessitava de um som que lhes remetesse a sua região. Com o advento do disco long-play no Brasil, em 1951, a quantidade de "artistas caipiras" cresceria de forma surpreendente, o que nos leva a considerar a década de 50 como bastante promissora para a moda de viola. Contudo, a classe média e a elite paulista rechaçavam esse estilo musical que, ao lado de frevos pernambucanos, marchas, sambas de carnaval, sambas de enredo, sambas- canção, baiões e canções românticas, em geral, ficou demarcado como produção destinada às grandes massas (TINHORÃO, 2013).

Tinhorão (2006) explica que toda produção artística exprime o nível cultural em que se situa o seu artista e, consequentemente, o seu consumidor. Como os autores do discurso de letras de moda de viola eram, em sua grande maioria, pessoas simples, sem formação escolar, que tinham de exercer outros cargos na capital para se sustentar, eram menosprezados pelas pessoas que se julgavam com um nível maior de cultura.

Essas considerações são plausíveis, principalmente no que concerne ao público do discurso de letras de moda de viola, dividido por Martins (1975) em três tipos: $1^{\circ}$ ) os recém-chegados do meio rural ou do interior, que estão em fase de adaptação à vida citadina. Não possuem rádio ou vitrola, ficando sujeitos a audições ocasionais em casa de parentes e vizinhos; $2^{\circ}$ ) os imigrados há mais tempo. Apesar de possuírem rádio ou televisão, não são os consumidores diretos da moda de viola; $3^{\circ}$ ) superada a fase inicial de adaptação do migrante, temos o consumidor, propriamente dito, deste estilo musical.

Havia, ainda, uma pequena parcela composta pela classe média paulista, que não assumia publicamente sua preferência, com receio de ser vítima de preconceito, pois a moda de viola era considerada música das classes menos favorecidas, segundo Nepomuceno (1998).

Ademais, fica evidente também o interesse da indústria do disco pelo discurso de letra de moda de viola, ao constatar o seu êxito na capital. Para termos uma ideia desse sucesso, Tinhorão (2013) menciona que esse estilo musical havia conquistado $40 \%$ do mercado do disco brasileiro, na década de 50. Além das emissoras de rádio, verificamos que o circo, teatro, cinema, gravações e turnês mantinham os artistas sertanejos em grande atividade. Algumas duplas chegaram, inclusive, a se apresentar no exterior, voltando com novos ritmos, que foram incorporados ao cancioneiro caipira.

A moda de viola, contudo, foi o estilo musical que resistiu a essas influências, mantendo-se fiel à sua origem. Pelo interdiscurso é possível identificarmos o atravessamento de discursos que permeiam a memória discursiva do homem caipira. Como é um conceito central nos estudos da AD, vamos discutir o interdiscurso no item a seguir. 


\section{CONSIDERAÇÕES SOBRE O PRIMADO DO INTERDISCURSO}

Considerado um princípio básico e central nas reflexões teóricas de Maingueneau (2008a, p.11), o interdiscurso, definido como "[...] um espaço de trocas entre vários discursos convenientemente escolhidos", é inscrito na perspectiva de uma heterogeneidade constitutiva, ou seja, que não é marcada na superfície linguística. Essa posição modifica a forma pela qual tomamos o discurso, pois ele não é autônomo, fechado em si mesmo, uma vez que é na relação com outras formações discursivas que ele se constitui.

Antes, vale lembrar que a noção de heterogeneidade constitutiva advém da proposta de Authier-Revuz (1990), a qual elabora uma teoria da enunciação que resulta numa concepção de discurso assentada na heterogeneidade da linguagem. Desse modo, a autora acena para dois tipos de heterogeneidade: a mostrada e a constitutiva.

A heterogeneidade mostrada permite que identifiquemos o Outro no nível linguístico, por meio de citações, aspas, discurso direto, autocorreções, alusões. Já a heterogeneidade constitutiva não expõe tais marcas, uma vez que essas estão diluídas no próprio interdiscurso.

Para uma melhor apreensão do que vem a ser interdiscurso, Maingueneau (2008a) propõe dividi-lo em universo discursivo, campo discursivo e espaço discursivo. A interação das formações discursivas de todos os tipos recebe o nome de universo discurso. Dada à impossibilidade de estudá-lo em sua totalidade, ele é dividido em campos discursivos. Tais campos consistem no conjunto de formações discursivas que se encontram em relação de concorrência, o que significa tanto afrontamento quanto aliança.

O recorte em campos é, antes de tudo, uma abstração necessária, que permite ao analista delimitar seu objeto de pesquisa e observar as regularidades sobre as formações discursivas existentes. Contudo, o discurso não se constitui da mesma maneira que todos outros discursos desse campo, o que o caracteriza como heterogêneo. Sendo assim, é preciso que os campos sejam recortados em subconjuntos, ou melhor, em espaços discursivos, os quais nos permitem compreender os discursos, dada sua concretude.

Esse espaço é definido pelo analista em função de seus objetivos na pesquisa. No caso de nossa pesquisa, o campo discursivo com o qual optamos por trabalhar é o literário e o espaço é o discurso de letra de moda de viola. O discurso em questão não se configura um bloco homogêneo, pois é atravessado por outros discursos que ora são aceitos, ora são negados. Portanto, é no espaço de trocas enunciativas, denominado interdiscurso, que se dá a análise.

O reconhecimento da primazia do interdiscurso contraria a posição que vigorou na AD nos anos 1960, com a qual os estudiosos visavam a revelar a identidade de cada formação discursiva, como se essa pudesse ser fechada em si mesma. Segundo Maingueneau (2008a, p.31)

[...] nesse quadro, a relação com outras formações discursivas não podia ser pensada, a não ser segundo o modo espontâneo da justaposição de unidades externas umas as outras. O interdiscurso aparecia como um conjunto de relações entre diversos "intradiscursos" compactos. Trata-se, desde então, de subverter essa equivalência entre exterior do discurso e interdiscurso, para pensar a presença do interdiscurso no próprio coração do intradiscurso.

$\mathrm{Na}$ realidade, não há como dissociar a interação dos discursos do funcionamento intradiscursivo, o que atesta o caráter essencialmente dialógico de todo enunciado. Além disso, é no espaço discursivo que todo enunciado do discurso rejeita um enunciado do seu Outro. Esses enunciados têm, conforme Maingueneau (2008a), um direito, relacionado com a formação discursiva da qual o sujeito pertence, e um avesso, que consiste na rejeição do discurso de seu Outro.

Diante do exposto, não há como o enunciador reivindicar a autonomia de seu discurso, visto que este é resultado da imbricação do Mesmo e do Outro. Maingueneau (2005, p.39) nos lembra de que o Outro não é um fragmento localizável ou da figura de um interlocutor. O Outro é “aquela parte de sentido que foi necessário que o discurso sacrificasse para constituir sua identidade”. Ele se 
encontra diluído na raiz de um Mesmo que, por sua vez, encontra-se descentrado em relação a si próprio. Mencionemos Maingueneau (2008a, p.36:37) para esclarecer que

[...] no espaço discursivo, o Outro não é nem um fragmento localizável, uma citação, nem uma entidade externa; não é necessário que ele seja localizável por alguma ruptura visível da compacidade do discurso. Ele se encontra na raiz de um Mesmo já descentrado em relação a si próprio, que não é em momento algum passível de ser considerado sob a figura de uma plenitude autônoma.

Em termos de gênese, os discursos nascem imbricados em uma relação dialógica, o que equivale dizer que não há discurso que não dependa do outro. Os discursos se formam de maneira regulada no interior do interdiscurso, onde se confirma a existência de uma zona de regularidade semântica, que estrutura o modo de coesão dos discursos. Isso impede que o discurso seja encarado como uma "dispersão de ruínas", nos dizeres do próprio Maingueneau (2008a, p.19).

Vale destacar que o cruzamento entre os diversos discursos só é possível graças a uma memória coletiva que inscreve o sujeito como ser social. Ressaltamos com Brandão (2004, p. 96), que não se trata de "[...] uma memória psicológica, mas de uma memória que supõe o enunciado inscrito na história". Embora os dizeres não sejam propriedades individuais, conforme atesta Orlandi (2005), eles são recuperados levando-se em consideração as formações discursivas a que o sujeito se filia.

\section{A CENOGRAFIA E O ETHOS DISCURSIVO}

Maingueneau (2009, p.250) propõe o conceito de cenas de enunciação, ao constatar que "[...] um texto é na verdade o rastro de um discurso em que a fala é encenada”. Nesse sentido, um texto não se resume a um conjunto de signos inertes dispostos simplesmente um ao lado do outro, isentos de qualquer propósito e estratégia.

Apreendida no interior dos enunciados, a cena de enunciação relaciona-se, também, com os dêiticos, responsáveis pelas coordenadas pessoais, espaciais e temporais. Essas não necessariamente coincidem com as circunstâncias de produção, ou situação de comunicação, do enunciado. A fim de compreendermos melhor o que vem a ser cena de enunciação, recorremos a três dimensões, a saber: cena englobante, cena genérica e cenografia, estabelecidas por Maingueneau (2005).

A cena englobante corresponde ao tipo de discurso e a cena genérica corresponde ao gênero de discurso. Contudo, Maingueneau (1997) reconhece que o conceito de gênero de discurso é de difícil manejo, uma vez que, frequentemente, encaixam-se os gêneros uns nos outros. Tentar empregar a tipologia herdada da retórica para distingui-los torna-se inoperante. Por isso, o linguista, dessa maneira, classifica os gêneros a partir da relação estabelecida entre a cena genérica e a cenografia.

A palavra cenografia nos remete imediatamente ao plano do teatro, com personagens atuando num cenário determinado. Para a $\mathrm{AD}$, a cenografia não é concebida como um cenário que já se apresenta pré-construído, determinado. Nos dizeres de Maingueneau (2005, p.87) "[...] a cenografia implica um processo de enlaçamento paradoxal, ou seja, é ao mesmo tempo a fonte do discurso e aquilo que ele engendra”.

Cada cena genérica permite a construção de uma cenografia que corresponda efetivamente ao acontecimento. Todavia, essa relação não é arbitrária, pois a cenografia não é imposta pelo tipo ou pelo gênero do discurso. Ela é instituída no e pelo próprio discurso. Dizemos isso porque há gêneros de discurso que suscitam a inspiração de cenografias cujo modelo se afasta do preestabelecido, como o discurso publicitário, que mobiliza cenografias variadas. O produtor de um anúncio publicitário pode optar por uma cenografia inesperada, ou seja, que a encenação de tal discurso ocorra por meio de um poema, para exemplificarmos. Da mesma maneira ocorre com o discurso literário, pois um romance pode ser enunciado por meio de uma cenografia de relato de viagem, de uma carta, etc. 
Diante disso, a cenografia inevitavelmente tem o encargo de passar a cena englobante e a cena genérica ao segundo plano, de modo que o coenunciador receba o texto num primeiro momento como relato de viagem e não como um romance. A cenografia explorada será bem sucedida quando o coenunciador, à medida que avançar no texto, convencer-se de que a cenografia engendrada é a mais adequada. Para que isso suceda, o conteúdo deve harmonizar-se com a cenografia, que tem o intento de lhe dar suporte. Contudo, nem sempre é possível que o coenunciador receba a cenografia que o produtor do discurso almeja. Ainda que seja identificada com base em índices localizáveis no texto, a cenografia não designa a si mesma; ela se mostra, fundamenta Maingueneau (2009).

Diante do que expusemos, reiteramos que a cenografia não deve ser encarada como um simples quadro. Atuando de forma dinâmica e criativa, ela acaba por englobar uma série de recursos linguístico-discursivos mencionados, para que faça sentido e conquiste a adesão do coenunciador a uma determinada formação discursiva. Outra contribuição da cenografia está no fato de estar integrada ao ethos discursivo.

Ao contemplar o estudo do ethos no quadro teórico da AD, Maingueneau (2001) inova, quando propõe que todo discurso, seja escrito ou oral, é sustentado por uma vocalidade, por meio da qual podemos reconhecer um enunciador encarnado. Para ele, há um enunciador que é responsável pelo que enuncia no texto e que difere do autor empírico. Embora alargue o conceito de ethos, Maingueneau (2008b) reconhece que sua perspectiva mantém proximidade com a Retórica de Aristóteles, principalmente, em relação aos seguintes aspectos:
I - O ethos é constituído por meio do discurso.
II - O ethos é um processo interativo de influências mútuas.
III - O ethos é uma noção sócio-discursiva, integrada a uma conjuntura sócio-histórica.

As razões que levaram Maingueneau (2001) a se interessar por essa noção se devem à reflexividade enunciativa e à relação entre corpo e discurso. A primeira age no sentido de não permitir que o texto seja considerado simplesmente um objeto a ser contemplado, posto que "[...] ele é enunciação, voltada para um co-enunciador que é necessário mobilizar para fazê-lo aderir 'fisicamente' a um certo universo de sentido", segundo Maingueneau (2005, p.73). A segunda se refere ao termo entre aspas na citação acima, ou seja, a uma corporalidade, que retomaremos nos parágrafos adiante.

Diferentemente do ethos aristotélico, na $\mathrm{AD}$, o ethos discursivo não se mostra, pois a enunciação se encarrega de colocá-lo em segundo plano. Isso quer dizer que o ethos é uma categoria que é desvelada no discurso.

Assim sendo, o ethos é concebido como uma instância cuja emergência se dá na cena de enunciação, não havendo, portanto, relação alguma com o orador ou com o escritor empírico do texto. Enfatizamos novamente que o ethos e a cenografia participam de um processo de enlaçamento que visa a validar a própria enunciação. Por isso, o ethos não pode ser tomado isoladamente. É neste ponto que reside a grande contribuição de Maingueneau (2001), ou seja, em considerar o ethos como constitutivo da cena de enunciação.

É importante salientar que, em AD, o ethos construído está associado ao processo de adesão dos sujeitos a um certo posicionamento e não somente à persuasão, como preceituava a retórica antiga.

Isso quer dizer que o ethos é um processo interativo, que visa a levar o outro a se identificar, além da dimensão verbal, com um corpo investido de valores socialmente aceitos ou rechaçados. Como todo texto escrito ou oral, é dotado de um tom, cuja função é dar autoridade ao que é dito; é por meio dele que o leitor constrói uma representação do corpo do enunciador. A instância subjetiva que emerge no discurso passa a desempenhar o papel de fiador, imputando-lhe a responsabilidade do que é dito.

Mesmo os textos que se recusam a mostrar a presença do enunciador são detentores de um fiador. Ao fiador, o enunciador atribui um caráter e uma corporalidade cujo grau de precisão varia segundo os textos. O caráter contempla os traços psicológicos e a corporalidade refere-se não somente à constituição física do corpo, mas também a uma maneira de se vestir e de se movimentar na sociedade. Vejamos que o conceito de ethos proposto por Maingueneau (2001) vai além da dimensão verbal, pois cinge sobre uma concepção mais encarnada do ethos. 
O caráter e a corporalidade provêm de um conjunto de representações sociais valorizadas ou desvalorizadas, sobre as quais se apoiam a enunciação. Maingueneau (2001) as denomina de estereótipos culturais, que pertencem aos domínios da literatura, fotos, cinema, publicidade etc. O ethos é, sem dúvida, de natureza híbrida, "[...] um comportamento socialmente avaliado que não pode ser apreendido fora de uma situação de comunicação precisa, integrada ela mesma numa determinada conjuntura sócio-histórica”. (MAINGUENEAU, 2008, p.17)

Conforme mencionamos, o coenunciador também tem um papel relevante e ativo, pois é ele quem incorpora o ethos do enunciador. Isso, de certa forma, justifica porque o ethos visado não é necessariamente o ethos produzido. Maingueneau (2005, p.75) explica esse "incidente", bastante frequente por sinal, ao afirmar que

O enunciador não é um ponto estável que se "expressaria" dessa ou daquela maneira, mas é levado em conta em um quadro profundamente interativo, em uma instituição discursiva inscrita em uma certa configuração cultural e que implica papéis, lugares e momentos de enunciação legítimos, um, suporte material e um modo de circulação para o enunciador.

Maingueneau (2008b) reconhece que o trabalho com o ethos envolve risco, por se tratar de uma categoria intuitiva, que não possui uma representação bem delimitada. Além disso, a afetividade do destinatário também está em jogo. Depreendemos que cada circunstância histórica é caracterizada por um ethos específico e que precisa ser retomada para que produza os efeitos desejáveis.

Retomando a forma pela qual o coenunciador incorpora o ethos discursivo, Maingueneau (2008b, p.18) a designa por incorporação, que atua sobre três registros inseparáveis:

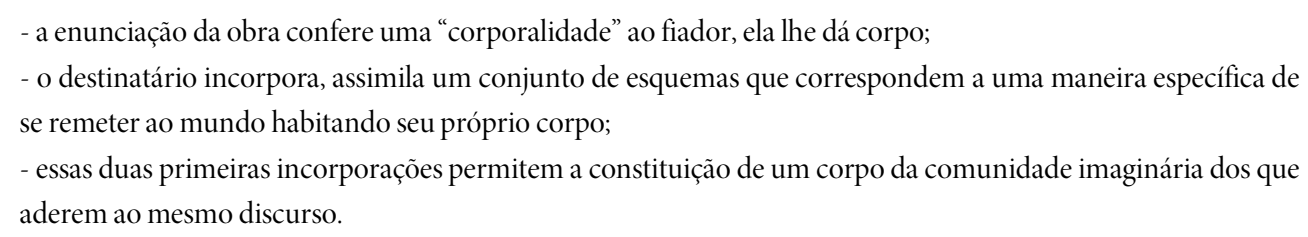

A incorporação não se restringe somente à identificação de um fiador na cena enunciativa; ela compreende um mundo ético, segundo Maingueneau (2008b), do qual o fiador faz parte. Por trás desse mundo ético, há situações estereotipadas que se associam a um comportamento e com as quais o coenunciador é levado a se identificar. Ademais, julgamos relevante apontar que o ethos, inserido na perspectiva da $\mathrm{AD}$, não confere ao enunciador liberdade de escolha quanto ao seu papel desempenhado, pois ele está subordinado às coerções que são determinadas pelo seu posicionamento. Não cabe, portanto, ao sujeito impor esses efeitos.

\section{ANÁLISE DO DISCURSO DA LETRA DE MODA DE VIOLA FERREIRINHA}

Considerado um clássico no cancioneiro caipira, o discurso de letra de moda de viola Ferreirinha permeia a memória discursiva dos sujeitos que cultuam esse estilo musical, sendo veiculado com intensidade nas regiões onde proliferou a cultura do homem caipira. Estamos, portanto, diante de um discurso que tem uma representatividade muito grande nesse espaço, consagrando-se como um arquivo da sociedade. Vamos à análise.

Este discurso produz uma cenografia que se configura em um relato, por meio do qual o enunciador narra um acontecimento fundado em uma experiência pessoal. Reiteramos que a cenografia tem o poder de colocar a cena englobante e a cena genérica em segundo plano, pois é com ela que o coenunciador entra em contato. Quanto à topografia, a cenografia remete ao campo e à cronografia, a um tempo passado, distante. Vejamos o recorte:

1 Eu tinha um companhero

2 Por nome de Ferreirinha

3 Nóis lidava com boiada 
4 Desde nóis dois rapaizinho

5 Fomos buscá um boi bravo

6 No campo do Espraiadinho

7 Era vinte o oito quilômetro

8 Da cidade de Pardinho

O recorte aponta o atravessamento do discurso do trabalho, mais especificamente do ofício de boiadeiro, conforme revelam os itens lexicais boiada e boi bravo. Diante disso, a memória discursiva do coenunciador reatualiza o estereótipo de boiadeiro, associado a um corpo rústico, forte e destemido. O enunciador assume a posição de empregado, visto que ele e o amigo cumprem ordens que lhes são atribuídas. O emprego da linguagem informal induz o coenunciador a incorporar a imagem de um corpo simples, destituído de estudos e status social.

Notemos que o relato evidencia um lugar e um sujeito que se distanciam da cidade, vivendo à margem dela. Pelas condições sóciohistóricas de produção do discurso da letra selecionado, verificamos que o migrante rural, embora morando na cidade, também se sentia descolado, marginalizado. É neste sentido que observamos uma relação entre enunciador e coenunciador.

A cenografia produzida gera expectativa no coenunciador sobre o que poderia ter ocorrido com Ferreirinha. O discurso evidencia a passagem do tempo e o cansaço do enunciador, anunciando um ethos preocupado. Diante disso, o coenunciador infere que algo de ruim ocorreu. Vamos ao recorte:
13 Já era de tardezinha
14 E eu já tava bem cansado
15 Não encontrava o Ferreirinha
16 E nem o tal boi arribado

Constatamos que, de fato, a cenografia é um processo interativo, que compreende o outro, envolvendo-o no relato também. No recorte a seguir, instala-se o conflito, que aplica movimento e dinamicidade na cenografia.
17 Naquilo avistei o potro
18 Que vinha vindo assustado
19 Sem arreio e sem ninguém
20 Fui ver o que tinha se dado

O discurso emprega um tom de suspense, reforçado pela marca lexical naquilo, marcador de mudança, que tem o objetivo de chamar a atenção do co-enunciador ao que está sendo narrado. O coenunciador, por sua vez, incorpora o ethos discursivo de um homem que tem habilidade em narrar um acontecimento. À medida que a cenografia avança, o discurso vai adquirindo um tom dramático, conforme o recorte:
25 Quando avistei Ferreirinha
26 Meu coração se desfeiz
27 Eu rolei do meu cavalo
28 Com tamanha rapidez
29 Chamava ele por nome
30 Chamei duas ou três veiz
31 E notei que tava morto
32 Pela sua palideiz

O enunciado 26 contrasta com o corpo rude e forte do enunciador, acrescentando-lhe ao caráter um ethos sentimentalista, enternecido com o incidente. O item lexical coração desperta no coenunciador comoção, uma vez que a memória discursiva popular estabelece um estreito vínculo entre o coração e as emoções humanas. Além de a cenografia apontar um corpo ágil e disposto a 
socorrer o amigo, revela um corpo que sofre com o ocorrido, por conta do laço de amizade entre o enunciador e o amigo Ferreirinha, que se estreita em razão do tempo em que trabalharam juntos. Segundo Straforini (2001), o companheirismo entre os boiadeiros que conduziam a tropa era proporcionado pelos longos meses que passavam juntos nas estradas.

Com efeito, deparamo-nos com o campo discursivo da amizade, do companheirismo. Depreendemos que o léxico companheiro visa a ressaltar que a amizade entre ambos ultrapassa o âmbito profissional. A cena enunciativa, portanto, constrói-se em torno da demonstração de amizade entre ambos.

\author{
33 Pra deixar meu companheiro \\ 34 É coisa que eu não fazia \\ 35 Deixar naquele deserto \\ 36 Alguma onça comia
}

Nos enunciados 33 e 34, desvela-se um tom enfático, que reveste um corpo convicto de sua atitude, pois em seu mundo ético não é permitido abandonar o amigo em hipótese alguma. A cenografia apóia-se, então, em uma cena validada de forma positiva na sociedade. Nesse sentido, a morte de Ferreirinha não é casual, pois põe à prova a demonstração de companheirismo e respeito por parte do enunciador.

Outro campo discursivo a atravessar esse discurso é o religioso, de viés católico, conforme o recorte:

\author{
37 Tava alí só eu e ele \\ 38 Deus em nossa companhia \\ 54 Quando eu cheguei no povoado \\ 55 Dexei na porta da igreja
}

Os enunciados acima demonstram a influência da religião, com seus princípios reguladores, sobre a prática discursiva do enunciador. Ao proceder dessa forma, desponta o ethos discursivo de um homem que crê em Deus e, que por isso, não se desespera diante do incidente. Com efeito, o coenunciador vai delineando um corpo que vive sob os preceitos da igreja.

A cenografia vai se desenvolvendo de modo a comprovar o ethos de companheiro que o enunciador reivindica. Vejamos o recorte:

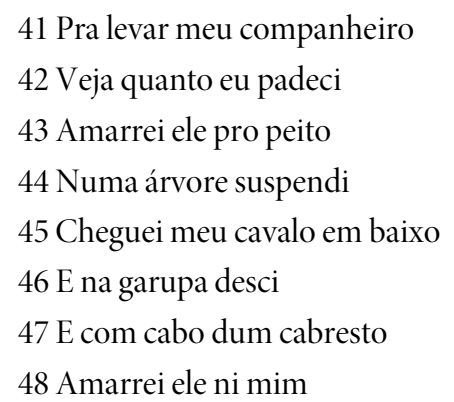

O enunciado 42 imprime um tom dramático à cenografia, tendo em vista destacar o esforço físico do enunciador para transportar o corpo do amigo. Destacamos que, nesse mesmo enunciado, o enunciador interage com o coenunciador para que seja testemunha de seu relato. Trata-se de uma estratégia para envolvê-lo e conquistar sua adesão. Nos enunciados seguintes, o relato emprega o mecanismo didático para descrever a façanha, evidenciando, com isso, todo o esforço e habilidade empreendidos na ação. Pelo modo de dizer do enunciador, emerge o ethos de um sujeito habilidoso, engajado, destemido e leal, que não mede esforços pelo outro. Para isso, a cenografia introduz um corpo físico que condiz com esse ethos discursivo.

É importante destacar que, embora o amigo Ferreirinha seja referendado no título do discurso dessa letra, é o enunciador que ganha destaque na cenografia. O discurso a produz tendo em vista evidenciar o ethos discursivo de companheiro do enunciador. Lembramos que o ethos discursivo é, deliberadamente ou não, aquilo que o enunciador mostra de si, e o lugar privilegiado para depreendê-lo é a cenografia. Portanto, é ela que legitima o ethos discursivo.

Em seguida, o recorte apresenta o desfecho do relato, cujo discurso tece um tom de lamúria, tristeza e saudades. 


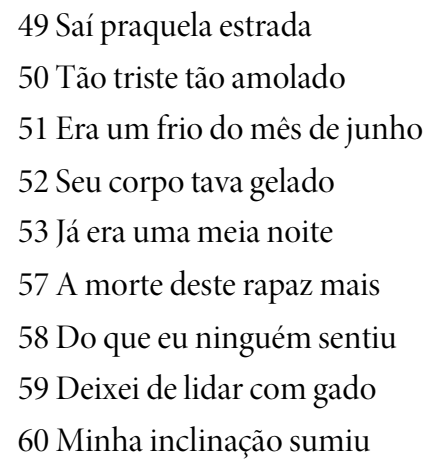

A cenografia engendrada endossa o sofrimento do enunciador, que se torna fiador de um corpo sensível, solidário. A cronografia apontada no enunciado 53 indica a passagem do tempo, ressaltada pelo item lexical Já. Os efeitos de sentido que emergem são de que o enunciador tem o intuito de impressionar o co-enunciador, uma vez que se envolveu em uma tarefa de difícil execução, que demandou habilidade, tempo e paciência. Para isso, o discurso extrapola a dor do enunciador, desvelando um ethos exagerado e dramático, como demonstra os enunciados 57 e 58.

Em seu mundo ético, o companheirismo é bastante valorizado, a ponto de o enunciador abandonar o ofício de boiadeiro. Mesmo as situações adversas empregadas na cenografia, como o fato do enunciador estar sozinho e seu companheiro morto, de ser noite e inverno, não o destituem da ideia de transportar o corpo até o povoado. Isso tudo, sem dúvida, incide de maneira positiva sobre o seu ethos.

Contudo, as condições sócio-históricas de produção desse discurso contrastam com esse ethos, pois o coenunciador depara-se com o mundo do trabalho perpassado pelo individualismo, pela competitividade, em razão do sistema capitalista vigente na sociedade.

Tendo em vista que o público da moda de viola era, em grande parte, o migrante rural, entendemos que a imagem do enunciador, construída no discurso da letra Ferreirinha, representa o sujeito empírico. Ao chegar à capital paulista, o migrante rural enfrentava problemas relacionados à acomodação e, principalmente, ao trabalho, segundo Durhan (1973). Além de não possuir qualificação técnica, o migrante rural sentia dificuldade em se ajustar a esse sistema de trabalho, pois contrariava o seu padrão cultural. Devemos considerar, ainda, que o migrante também deparou-se com o estereótipo negativo, disseminado que o rotulava de ignorante e atrasado.

Diante disso, o discurso da letra que selecionamos desvela a imagem de um sujeito cujos valores se configuram em práticas discursivas que pertencem à cultura do migrante rural. Esses valores foram revelados pelo interdiscurso, o qual contempla o atravessamento dos discursos do trabalho, da religião e do companheirismo, atestando o caráter essencialmente dialógico de todo o discurso. A intersecção desses discursos na cenografia não é aleatória, pois incide sobre o ethos discursivo do enunciador de maneira positiva.

\section{CONSIDERAÇÕES FINAIS}

Nesse trabalho, propusemo-nos a investigar a constituição do ethos discursivo na letra de moda de viola intitulada Ferreirinha. Advinda dos estudos de Maingueneau (1997, 2008b), a categoria ethos discursivo mostrou-se bastante propícia e eficaz para identificarmos a imagem do enunciador construída no e pelo discurso e, com efeito, o processo de adesão.

Verificamos que a cenografia criada configura-se em um relato que faz emergir um ethos discursivo baseado em valores e estereótipos validados socialmente, principalmente, pelos migrantes rurais. É nesse espaço que os migrantes rurais se veem e se constituem, revertendo o estereótipo negativo que o homem citadino lhes infligiu. Mais do que um estilo musical, o discurso da letra de moda de viola consiste em uma prática discursiva que revela fatores identitários e culturais do migrante rural. 
Isso corrobora a importância da cenografia no discurso, pois é ela que o legitima, de modo a conciliar conteúdo e ethos discursivo. Além disso, comprovamos que os discursos nascem imbricados em outros, não sendo possível precisar-lhes uma origem. Atravessado pelo discursivo do trabalho, da religião e do companheirismo, o interdiscurso incide também de maneira positiva sobre a construção do ethos discursivo do enunciador. Ainda que seja uma instância discursiva, vemos, portanto, uma identificação entre o enunciador e o migrante rural.

\section{REFERÊNCIAS}

AUTHIER-RÉVUZ, Jacqueline. Heterogeneidades(s) enunciativas(s). Trad.C.M.Cruz e J.W.Geraldi. Cadernos de Estudos Linguísticos, Campinas, nº 19, 1990, p. 25-41.

BRANDÃO, Helena Nagamine. Introdução à análise do discurso. 2. ed. Campinas, SP: UNICAMP, 2004.

DURHAN, Eunice R. A caminho da cidade: a vida rural e a migração para São Paulo. São Paulo: Editora Perspectiva, 1973.

MAINGUENEAU, Dominique. Novas tendências em análise do discurso. 3.ed. Campinas: Pontes, 1997.

O contexto da obra literária. Trad. Marina Appenzelles. São Paulo: Martins Fontes, 2001.

. Análise de textos de comunicação. 4.ed. São Paulo: Cortez, 2005.

Gênese dos discursos. Trad. Sírio Possenti. São Paulo: Parábola, 2008a.

. A noção de ethos discursivo. In. MOTTA, Ana Raquel, SALGADO; Luciana (Org.) Ethos discursivo. São Paulo: Contexto, 2008b. p.11- 29.

Discurso literário. São Paulo: Contexto, 2009.

MARTINS, José de Souza. Capitalismo e tradicionalismo: estudos sobre as contradições da sociedade agrária no Brasil. São Paulo: Pioneira, 1975.

NEPOMUCENO, Rosa. Música caipira: da roça ao rodeio. 2. ed. São Paulo: Ed. 34, 1999.

ORLANDI, Eni Pucinelle. Análise do discurso: princípios e procedimentos. 6. ed. Campinas, São Paulo: Pontes, 2005.

PÊCHEUX, Michel. A análise do discurso: três épocas. In: GADET, Françoise; HAK, Tony. por uma análise automática do discurso: uma introdução à obra de Michel Pêcheux. 2. ed. Campinas: EDUNICAMP, 1993. p.311- 318.

STRAFORINI, Rafael. No caminho das tropas. Sorocaba, São Paulo: TCM, 2001.

TINHORÃO, José Ramos. Cultura popular: temas e questões. 2.ed. São Paulo: Editora 34, 2006. . A música sertaneja. In: Pequena história da música popular segundo seus gêneros. 7.ed. São Paulo: Editora 34, 2013. p.211- 223 . 